\title{
Natural infection of Trypanosoma cruzi in a dog with heart lesions: a case report from Malinalco, State of Mexico, Mexico
}

This article was published in the following Dove Press journal:

Research and Reports in Tropical Medicine

25 November 2010

Number of times this article has been viewed

\begin{abstract}
A Barbabosa-Pliego'
V Velázquez-Ordóñez'

MC López-Rosas'

MU Alonso-Fresán'

E Burgos-Aparicio'

L Ochoa-García ${ }^{2}$

$\checkmark$ Camacho-Sierra'

C Guzmán-Bracho ${ }^{3}$

S Martínez-Castañeda'

RC Fajardo-Muñoz'

JG Estrada-Franco ${ }^{4,6}$

NJ Garg ${ }^{4,5}$

JC Vázquez-Chagoyán'

'Centro de Investigación y Estudios Avanzados en Salud Animal, Facultad de Medicina Veterinaria y Zootecnia Universidad Autónoma del Estado de México, Toluca, México;

${ }^{2}$ Laboratorio Estatal de Salud Pública del Instituto Salud del Estado de México; ${ }^{3}$ Instituto de Diagnóstico y Referencia Epidemiológicos, SSA, Mexico; ${ }^{4}$ Departments of Pathology, ${ }^{5}$ Microbiology and Immunology, University of Texas Medical Branch, USA; 'Universidad Autónoma de Chiapas, Tapachula, Chiapas, México
\end{abstract}

Correspondence: Juan Carlos VázquezChagoyán

Centro de Investigación

y Estudios Avanzados en Salud Animal,

Facultad de Medicina Veterinaria

y Zootecnia Universidad Autónoma

del Estado de México Autopista

Toluca-Atlacomulco Km 15.5,

Toluca, Estado de México,

50200, México

Email jcvch@yahoo.com
Background: Chagas disease is widely distributed in tropical and subtropical regions of the Americas, including more than $50 \%$ of the Mexican territory. The southern region of the State of Mexico (the Tejupilco Sanitary Jurisdiction) was recently reported as endemic; however the pathogenicity of the circulating strains has not been studied in depth. Recent studies have reported Trypanosoma cruzi seropositive dogs in the villages of Malinalco and Zumpahuacan in the central south of the State of Mexico. Dogs are epidemiologically important, because the evolution of symptoms and pathology of Chagas disease in this vertebrate mimics the human disease, and because dogs maintain the domestic cycle of parasite transmission.

Objectives: To study the clinical and pathological findings of a dog showing serological evidence of $T$. cruzi infection. The study of the canine, identified in the Malinalco locality, is expected to contribute to the general characterization and behavior of the pathogen in the region.

Methods: Clinical (electrocardiogram, echocardiogram and clinical exam), pathological (necropsy and histopathology) and serologic (indirect hemagglutination test and enzyme-linked immunoassay) analyses were conducted in a 4-year-old dog naturally infected with $T$. cruzi.

Results: The canine was diagnosed with dilated cardiomyopathy and hepatomegaly associated with congestive cardiac insufficiency, presumably provoked by chronic myocarditis and derived from natural infection with $T$. cruzi.

Conclusion: T. cruzi strains circulating in the village of Malinalco, State of Mexico are pathogenic for dogs, and could be affecting other domestic animals, and even infecting humans in the region.

Keywords: Trypanosoma cruzi, Chagas disease, cardiomyopathy, dog, natural infection, Malinalco, State of México

\section{Introduction}

American trypanosomiasis, a disease caused by Trypanosoma cruzi, is widely distributed in South and Central America, Mexico and southern US states. An estimated 18 million people are infected, and $>100$ million are estimated to be at risk of infection in endemic regions. ${ }^{1,2}$ In Mexico, the Mexican Health Ministry has estimated that about 1.6 million people might be infected with $T$. cruzi. This estimate is based on a results of a national serosurvey conducted between 1987 and 1989, when seropositive samples were detected in most of the country, and a seroprevalence of $1.6 \%$ in Mexico was reported at a national level. ${ }^{3,4}$ At this time the State of Mexico, located in central Mexico, was considered free of T. cruzi transmission. ${ }^{5}$ Recently studies conducted by our group have noted endemic T. cruzi transmission in several rural areas in southern State of Mexico. ${ }^{6,7}$ Malinalco, a 
small town (population 22,970) in southern State of Mexico, is a subtropical tourist resort. Physiogeographic conditions show a rainy season during the summer with an average precipitation of $1177 \mathrm{~mm}$ and an annual average temperature of $20^{\circ} \mathrm{C}$. It is located at $19^{\circ} 57^{\prime} 07^{\prime \prime} \mathrm{N}, 99^{\circ} 30^{\prime} 06^{\prime \prime} \mathrm{W}$, at an altitude of $1750 \mathrm{~m}$ (Figure 1$)^{8}$. Local health authorities, as well as our group, have found T. cruzi-infected Triatoma pallidipenis widespread in this region (unpublished observations). No other triatomine species except a few samples of $T$. dimidiata have been found in this region, no human or animal epidemiological studies have been published and very little is known about the virulence of the parasites circulating in Malinalco and neighboring areas. Dogs have been considered indicators of T. cruzi infection for humans, since both species are exposed to the triatomines, and infected via contamination of mucosa or skin abrasions during a blood meal by the vector. ${ }^{3,9,10}$ Dogs and humans also share clinical signs of the disease, including electrocardiographic (EKG) and echocardiographic (ECG) alterations indicative of dilated cardiomyopathy and right cardiac insufficiency. Acute infection by T. cruzi, in general, results in nonspecific symptoms, and $<5 \%$ of individuals develop myocarditis. After immune control of parasitemia, a majority $(>95 \%)$ of infected patients enter an indeterminate stage, with no clinical symptoms. Several years later, about $30 \%$ of the infected patients develop asymptomatic, progressive and irreversible cardiomyopathy, and lymphoadenopathy associated with sudden death. ${ }^{11-13}$ Here we discuss the main clinical and pathological findings of a seropositive dog exposed to natural $T$. cruzi infection, which was apparently infected within the house where it lived, in the village of Malinalco. The dog used to live with a middle-class, well-educated family diagnosed as free of infection by the health authorities. This is the first veterinary case report of a dog with Chagas disease in this subregion of the State of Mexico.

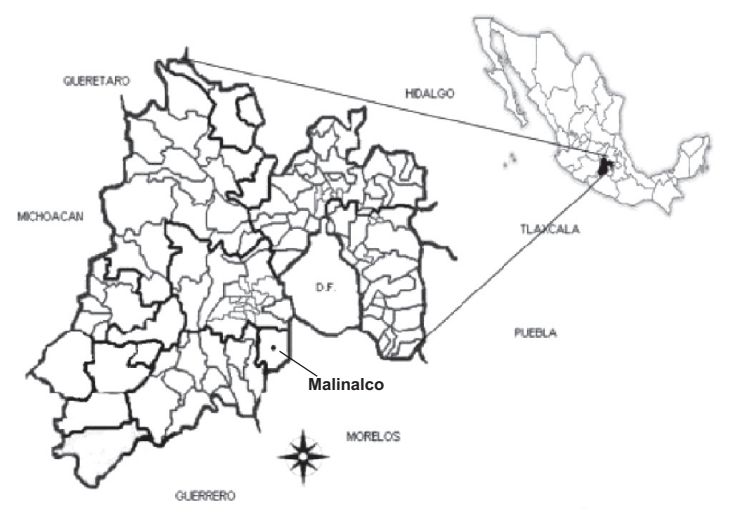

Figure I Location of Malinalco, State of Mexico, Mexico.

\section{Methods and materials}

A 4-year-old female cross-breed dog from Malinalco, State of Mexico, was donated for this study after being diagnosed positive for $T$. cruzi infection through two serologic assays: indirect hemagglutination (IHA) test and enzyme-linked immunosorbent assay (ELISA). Two commercial serologic kits were used to detect anti-T. cruzi antibodies: IHA (Polichaco ${ }^{\circledR}$ Laboratorio Lemos SRL, Buenos Aires, Argentina) (with 98\% sensitivity and 99\% specificity for Trypanosoma, according to the manufacturer's specifications) and ELISA (Laboratorio Lemos SRL, Buenos Aires, Argentina) (with $100 \%$ sensitivity and $100 \%$ specificity for Trypanosoma, according to the manufacturer's specifications). These assays were performed as published elsewhere. ${ }^{6,13}$ Clinical evaluation included routine exams: body temperature, pulmonary, digestive, cardiac systems and superficial lymph nodes inspection, and cardiac and pulmonary evaluations before and after exercise. Also hemogram, EKG and ECG were conducted before humanitarian sacrifice of the animal following a protocol approved by the Animal Bioethics Committee of the Facultad de Medicina Veterinaria y Zootecnia de la Universidad Autónoma del Estado de México and according to the norm of the Mexican Federal Health authorities. ${ }^{14}$ Necropsy was performed by routine diagnostic procedures of the Centro de Investigacion y Estudios Avanzados en Salud Animal. All organs were inspected, but special attention was paid to right and left ventricle walls and to the interventricular septum of the heart. Tissue samples from all organs were fixed in formalin $(10 \%, \mathrm{pH} 7.2)$ and processed for paraffin inclusion. Tissue sections $(5 \mu \mathrm{m})$ were stained with hematoxylin and eosin stain, and 25 fields from each section were evaluated by light microscopy.

\section{Results}

At time of clinical evaluation, the dog's temperature was normal at $38^{\circ} \mathrm{C}$, precural lymphonodes were slightly swollen and conjunctives were pale. After exercise, right atrialventricular murmur and light panting were noticed. Blood analysis showed hemolytic type II regenerative anemia, with slight leukocytosis and lymphocytosis. Serum IgG antibodies against $T$. cruzi were detected through IHA (1:16 dilution) and ELISA (1.933 vs $0.145 \mathrm{OD}_{450}$ values, patient vs control serum, 1:50 dilution). ECG showed changes in the left electrical axis with hemiblock of the anterior left branch of the bundle of His, and atrial dilatation (Figure 2). ECG (not shown) revealed a pronounced right ventricular dilatation. Main postmortem findings were: moderate hydrothorax and hydropericardium, 


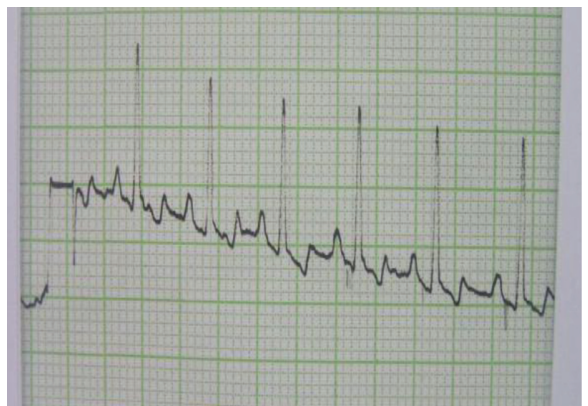

Figure 2 Electrocardiographic abnormalities found in a 4-year-old dog from Malinalco infected naturally with $T$. cruzi. Electrocardiographic recordings taken at $25 \mathrm{~mm} / \mathrm{s}$. I mm $=0.04$ seconds, I cm $=1 \mathrm{mV}$. Lead II recordings are shown. EKG shows right atrium conduction alterations as suggested by the peak shape $\mathrm{P}$ waves.

confirmed cardiomegaly and right-side cardiac dilatation (Figure 3). Some white bands and foci on the epicardium, myocardium and endocardium, suggesting cardiac necrosis, were seen over the right ventricle, apical region and left ventricle. Hepatomegaly, hepatic congestion and enlarged lymph nodes were also found. Histological evaluation demonstrated severe multizonal mononuclear infiltration in myocardium interstice, discrete fibrosis (Figure 4a) and amastigotes nests surrounded by mononuclear cells (Figure 4b). Other findings included sinusoids hepatic congestion of the central vein, vacuolization of hepatocytes, severe spleen congestion and diffuse lymph nodes hyperplasia. No macroscopic or microscopic lesions were found in digestive tract.

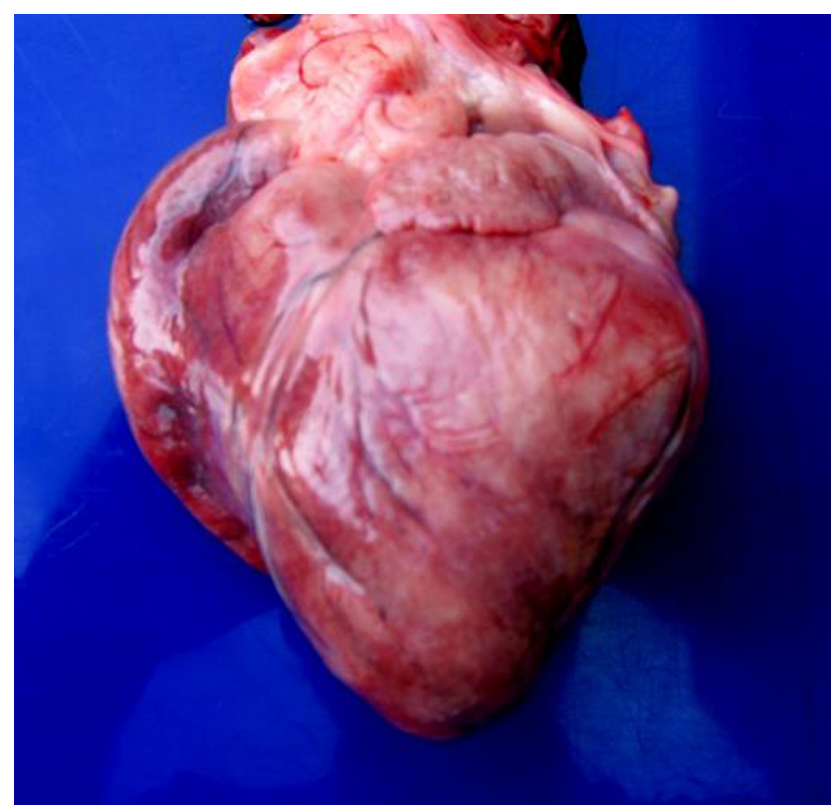

Figure 3 Morphologic alterations of chagasic heart from a 4-year-old dog from Malinalco infected naturally with $T$. cruzi. Heart morphology shows ventricular dilated cardiomyopathy (white arrow) and presence of pale areas indicates necrotic foci (black arrow).
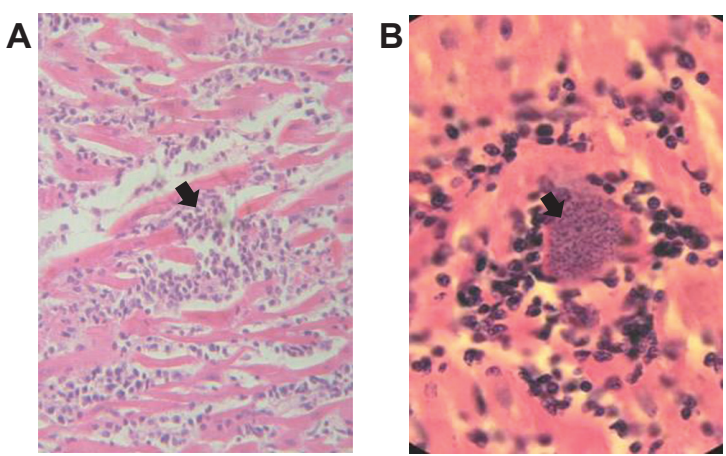

Figure 4 Heart histopathological findings from a 4-year-old dog from Malinalco infected naturally with $T$. cruzi. Heart tissue sections stained with hematoxylin and eosin. A) Note the infiltration of mononuclear cells (arrow) in myocardial section $(40 \times)$. B) Amastigotes nest (arrow) infecting a cardiomyocyte surrounded by inflammatory mononuclear cells can be observed $(100 \times)$.

\section{Discussion and conclusion}

In this report, a clinical dilated cardiomyopathy caused by T. cruzi in a naturally infected dog from Malinalco, State of Mexico, is described. This report is relevant because Malinalco is located adjacent to a geographic region recently reported as endemic. ${ }^{6,7,13}$ Although during the period 2002-2009 the state health authorities, as well as our group, found in Malinalco triatomines infected with T. cruzi through fecal sample examination (unpublished data), the virulence of the parasites circulating in the area had not been previously evaluated. The dog was first diagnosed by serology, clearly demonstrating anti-T. cruzi specific antibodies. Hemogram indicated anemia, a characteristic that has been observed in humans and animals during acute infection. ${ }^{15-17}$

Electrocardiographic studies suggested right atrium dilation and hemiblock, and second-degree atrioventricular block (Mobitz II) associated with cardiac failure. ECG showed a volume increment in the right ventricle chamber as well as a thinning of the free wall. Altogether, EKG and ECG findings were suggestive of right atrium and ventricle dilatation and myocarditis. These findings show some similarity to clinical and pathological findings in human patients with Chagas disease, in whom electrical alterations in the cardiac impulse such as left bundle branch block and atrial-ventricular block, as well as right ventricle dilation have been reported. ${ }^{2}$ The anatomopathological findings validated the clinical findings, and provided evidence of dilated chagasic cardiomyopathy. The left ventricle hypertrophy likely resulted in compensated cardiac insufficiency. Histopathology confirmed the cardiac lesions related to necrosis and inflammation (zonal nonsuppurative myocarditis) that have also been associated with chagasic lesions. ${ }^{17-20}$ In summary, this short report 
demonstrates the presence of $T$. cruzi infection and dilated cardiomyopathy in a dog from Malinalco, and suggests that the $T$. cruzi circulating in this region is pathogenic. Further epidemiologic studies should be conducted to determine the risk of T. cruzi infection for human and domestic animals in this tourist region.

\section{Acknowledgment}

This work was supported, in part, by grants from the Universidad Autónoma del Estado de México, (UAEMex, 2681/2008E) and from (CONACYT México 84863/2008).

\section{Disclosure}

The authors report no conflicts of interest.

\section{References}

1. World Health Organization 2008. Control of Chagas disease: second report of the WHO expert committee. In World Health Organization, Technical Report Series 905, UNDP/World Bank/WHO, Geneva, Switzerland. http://whqlibdoc.who.int/trs/WHO_TRS_905.pdf

2. Rassi A Jr, Rassi A, Little WC. Chagas heart disease. Clin Cardiol. 2000;23:883-889.

3. Guzman-Bracho C. Epidemiology of Chagas disease in Mexico: an update. Trends Parasitol. 2001;17:372-376.

4. Velasco-Castrejón O, Valdespino J, Tapia C, Salvatierra B, GuzmánBracho C, Magos C. Seroepidemiología de la enfermedad de Chagas en México. [Chagas disease seroepidemiology in Mexico] Salud Publica Mex. 1991;34:186-196.

5. Dumontiel E. Update of Chagas disease in Mexico. Salud Publica Mex. 1999;41:322-327.

6. Estrada-Franco JG, Bhatia V, Díaz-Albiter H, Ochoa-García L, Barbabosa A, Vázquez-Chagoyán JC, et al. Human Trypanosoma cruzi infection and seropositivity in dogs, Mexico. Emerg Infect Dis. 2006; 12:624-630.

7. Barbabosa-Pliego A, Campos-Gil P, Olivares Hernández D, et al. Prevalence of Trypanosoma cruzi and Triatomines during 2008 in a Sanitary Region of state of Mexico, Mexico. Vector-Borne Zoonotic Dis. 2010. In press.

8. INEGI. Censo General de Población y Vivienda. [Population and Housing General Census] In: Instituto Nacional de Estadística, Geografía e Informática, INEG. 2005. http://galileo.inegi.org.mx/website/mexico/ viewer.htm?b. sqTable $=77 \&$ bsq Field $=$ CVEMUN\&bsqStr $=15052 \& \mathrm{~T}$ Name $=M G M \&$ seccionB=mdm Malinalco.

9. Gurtler RE, Cecere MC, Castanera MB, Canale D, et al. Probability of infection with Trypanosoma cruzi of the vector Triatoma infestans fed on infected humans and dogs in northwest Argentina. Am J Trop Med Hyg. 1996;55, 24-31.
10. Jimenez-Coelho M, Poot-Cob M, Ortega-Pancheco A, et al. American trypanosomiasis in dogs from an urban and rural area of Yucatan, Mexico. Vector Borne Zoonotic Dis. 2008;8:755-761.

11. Carrasco V, Andrade LW, Jercic L, Lupsi MI. Estudio clínico y determinación de la parasitemia en un grupo de pacientes infectados por Trypanosoma cruzi de la región de Atacama, Chile. [Clinical study and parasitemia determination in a group of patients infected with Trypanosoma cruzi from the Atacama region, Chile] Rev Méd Chil. 2003;31:881-886.

12. Sisson D, O'Grady MR, Calvert CA. Myocardial diseases of dogs. Fox PR, Sisson D, Moïse NS, editors. In: Textbook of Canine and Feline Cardiology: Principles and Clinical Practice. Philadelphia, PA: WB Saunders; 1999:955

13. Barbabosa-Pliego A, Díaz-Albiter HM, Ochoa-García L, AparicioBurgos E, López-Heydeck S, Velásquez- Ordoñez V, et al. Trypanosoma cruzi circulating in the southern region of the State of Mexico (Zumpahuacán) is pathogenic: a dog model. Am J Trop Med Hyg. 2009;81:390-395.

14. Norma Oficial Mexicana NOM-033-ZOO-1995, Sacrificio humanitario de los animales domésticos y silvestres (07-16-96). [Official Mexican Norm NOM-0330ZOO-1995, Humanitarian Sacrifice of Domestic and Wild Animals] http://www.ocetif.org/archivos/NOM-033-ZOO-1995. doc. Accessed 2009 Dec 13.

15. Cardoso JE, Brener Z. Hematological changes in mice experimentally infected with Trypanosoma cruzi. Mem Inst Oswaldo Cruz. 1980; 75:97-104.

16. Marcondes MC, Borelli P, Yoshida N, Russo M. Acute Trypanosoma cruzi infection is associated with anemia, thrombocytopenia, leukopenia, and bone marrow hypoplasia: reversal by nifurtimox treatment. Microbes Infect. 2000;2:347-352.

17. Malvezi AD, Cecchini, R, de Souza F, Tadokoro CE, Rizzo LV, Pinge-Filho P. Involvement of nitric oxide (NO) and TNF-alpha in the oxidative stress associated with anemia in experimental Trypanosoma cruzi infection. FEMS Immunol Med Microbiol. 2004;41:69-77.

18. Pizzi TWA, Villagra O, Muñoz VS, Ortiz ZS, Solari ID. Concordancia de lesiones histológicas enratones infectados por dos poblaciones de Trypanosoma cruzi de Chile. [Concordance of histologic lesions in mice infected with two populations of Trypanosoma cruzi in Chile] Rev Med Chil. 2005;133:432-438.

19. Guedes PM, Veloso VM, Caliari MV, Carneiro CM, Souza SM, de Lana M, et al. Trypanosoma cruzi high infectivity in vitro is related to cardiac lesions during long-term infection in Beagle dogs. Mem Inst Oswaldo Cruz. 2007;102:141-147.

20. S. de Aluja A. Miocarditis por Trypanosoma cruzi en un perro. [Myocarditis caused by Trypanosoma cruzi in a dog] Rev Vet Mex. $1985 ; 16: 41-44$.
Research and Reports in Tropical Medicine

\section{Publish your work in this journal}

Research and Reports in Tropical Medicine is an international, peerreviewed, open access journal publishing original research, case reports, editorials, reviews and commentaries on all areas of tropical medicine, including: Diseases and medicine in tropical regions; Entomology; Epidemiology; Health economics issues; Infectious disease; Laboratory

\section{Dovepress}

science and new technology in tropical medicine; Parasitology; Public health medicine/health care policy in tropical regions; and Microbiology. The manuscript management system is completely online and includes a very quick and fair peer-review system. Visit http://www.dovepress. com/testimonials.php to read real quotes from published authors. 